\title{
Exploring Knowledge Translation in Occupational Health using the Mental Models approach: a case study of machine shops.
}

\author{
A-M Nicol \& A.C. Hurrell \\ University of British Columbia Centre for Health and Environment Research, Vancouver, British Columbia, \\ Canada
}

ABSTRACT: The field of knowledge translation and exchange is growing, particularly in the area of health services. Programs that advance "bench-to-bedside" approaches have found success in leveraging new research into a number of medical fields through knowledge translation strategies. However, knowledge translation remains an understudied area in the realm of occupational health, a factor that is interesting because workplace health research is often directly applicable to risk reduction activities. This research project investigated knowledge translation in one occupational setting, small machine shops, where workers are exposed to metal working fluids (MWF) which are well established dermal and respiratory irritants. Using the mental models approach, influence diagrams were developed for both scientists and were compared with qualitative interview data from workers. Initial results indicated that the sphere of influence diagrams would benefit from the inclusion of other stakeholders, namely policy makers and product representatives. Overall, findings from this research suggest that there is only minimal transfer of scientific knowledge regarding the health effects of metal working to those at the machine shop level. A majority of workers did not perceive metal working fluids to be hazardous to their health. Of note was the finding that MWF product representatives were rated highly as key sources of risk information. The translation of scientific knowledge to this occupational setting was poor, which may be due to varying perceptions and prioritizations of risk between stakeholders, lack of avenues through which communication could occur, an absence of accessible risk information and the small size of the workplaces. The mental models approach proved successful for eliciting information in this occupational context.

\section{INTRODUCTION}

Work is a central feature of life for most adults, providing our livelihood and sense of place, and occupying at least a third of our waking hours. Not surprisingly, work can have a profound impact on health. There is growing recognition that many diseases (e.g., asthma and chronic obstructive lung disease, joint and tendon disorders, stress-related mental health problems, and some cancers and communicable diseases) can be caused or augmented by workplace exposures.

Because of its vital role in adult life, the workplace provides a valuable opportunity for promoting occupational health. A key feature of occupational health research is that it is often possible to translate research results into direct prevention activities in the workplace. Thus, the communication or transfer of occupational health risk information has the potential to have an immediate and profound effect on work-related morbidity and mortality.

The process of communicating risk information to workplaces involves workers, managers, engineers, researchers, health experts, decisionmakers, regulatory bodies and governments. Although most occupational health researchers are aware of the need to communicate with front-line workers and decision-makers, there has been little research on knowledge translation or risk communication processes within occupational settings. To date, understanding the factors affecting the application of knowledge in this field remains extremely limited.

The primary objective of this research was to investigate how health information is translated in one occupational setting, machine shops, where workers are exposed to complex mixtures of chemical and biological hazards in the form of metal working fluids (MWFs). These exposures have been linked to occupational asthma, increased nonallergic airway responsiveness to irritants, chronic airflow obstruction and bronchitis symptoms (Cox et 
al., 2003) and have been the focus of considerable recent regulatory attention in Canada and the US. This project is linked to an ongoing study of risk factors for lung disease among tradespeople in British Columbia, Canada, which has found machinists to be at higher levels of risk for lung problems than three other trade groups (Kennedy, Chan-Yeung, Teschke, \& Karlen, 1999). Using interview data from experts, workers and managers, this project aimed to identify knowledge gaps and misperceptions about metal working fluid exposure, to determine socio-cultural and organization factors that influence how knowledge is transferred in an occupational context and to determine preferred channels or pathways for health risk communication.

\section{METHODS}

\subsection{Data Collection}

Data was collected for this project using the Mental Models methodology developed by Morgan et al at Carnegie Mellon University (Morgan, 2002). This method has been previously applied in an occupational context (Cox et al., 2003; Niewohner, Cox, Gerrard, \& Pidgeon, 2004b). The data was collected in two phases, beginning with interviews with scientific experts in the field of MWF exposure and effects, followed by interviews with workers employed in machine shops.

\subsubsection{Expert Interviews}

A member of the study team who is an academic expert on the health effects of MWF compiled a list of experts on MWF and health effects. The list was comprised primarily of academic researchers from the US and Europe, but also included US government researchers and occupational health professionals. Of this list of experts, the study team was able to contact 16 , and 10 of these consented to participate.

The interviews, which were carried out by a single trained research assistant, were conducted over the phone and lasted for an average of 30 minutes. The first two interviews were used to pilot test the survey instrument and were therefore not included in the final analysis. The respondents were asked open-ended questions about exposures, health effects, and mitigation strategies relating to MWF in the workplace. They were also asked about their attitudes and practices relating to the communication of their research results to decision-makers in industry and regulatory agencies.

\subsubsection{Worker Interviews}

To recruit machinists, introductory letters were sent to 130 machine shops in the province of British Columbia, Canada, and were followed up with at least one phone call. Twenty-nine workers from 15 different machine shops agreed to participate in an interview.

The interviews were conducted by four different trained interviewers. Twenty of the interviews were done at a private location at the worksite, and nine were done over the phone. Each interview took approximately 20-35 minutes. The respondents were asked open-ended questions that were created using guidance from the expert's Mental Model (see 2.2). Workers were queried about their work history and habits, as well as their knowledge of MWF exposure and the personal protection strategies they undertook in the workplace. They were also asked questions about health effects associated with MWFs, including where they would look for information on health effects, and what steps they would take to mitigate these effects. These openended questions were often followed up by probes designed to elicit more information on a particular subject matter.

\subsection{Mental Model Development}

All interviews were audio-taped and transcribed and entered into NVivo. To construct the expert model, transcripts from the expert interviews were coded with a coding schema developed through an iterative process of fitting the codes to the data, based on grounded theory (Strauss \& Corbin, 1998) and informed by previous mental models work (Cox et al., 2003; Niewohner, Cox, Gerrard, \& Pidgeon, 2004a). The coding schema was also informed by a literature review of existing chemical information regarding MWFs, which aided in the development of the model categories included in the expert mental model (i.e. exposure processes, machine types, etc.). The initial coding schema was reviewed and validated by an expert who was part of the research team.

The expert mental model covered five main domains: shop health and safety factors, MWF exposure factors, regulatory and economic factors, health effects, and exposure modes. Within these five broad categories, related topics, such as information sources, reactive behaviors, and physical safety barriers emerged as sub-categories. 
The transcripts from the worker interviews are currently being analyzed using a similar grounded theory-informed method. A worker mental model is currently under construction.

\subsection{Data Analysis}

For the health effects and information sources analysis, data for each of these constructs was abstracted from NVivo and reviewed by two members of the research team who had expertise in the areas of health effects and risk communication. Data from the workers were compared and contrasted with the expert model and areas of both congruence and disconnect were identified. Results were entered into tables to present comparisons.

\section{RESULTS}

\subsection{Demographics}

Respondents from the 15 participating machine shops were all male, and represented a range of ages and levels of experience in the trade. The demographic details of the machinist respondents can be found in Table 1 .

Table 1. Machinist demographics

\begin{tabular}{llll}
\hline Characteristic & & $\#$ & $\%$ \\
\hline Age & $20-29$ & 3 & $10 \%$ \\
$30-39$ & 10 & $34 \%$ \\
$40-49$ & 12 & $41 \%$ \\
$50+$ & 2 & $7 \%$ \\
\# of Years in trade & Unknown & 2 & $7 \%$ \\
& 5 to 10 & 7 & \\
& 11 to 15 & 7 & $24 \%$ \\
16 to 20 & 6 & $24 \%$ \\
21 plus & 7 & $21 \%$ \\
Unkown & 2 & $25 \%$ \\
Shop Size & & & $7 \%$ \\
& 10 people & 5 & $17 \%$ \\
Types of Machines & people & 13 & $45 \%$ \\
& 50 plus & 10 & $35 \%$ \\
& Unknown & 1 & $3 \%$ \\
& Manual & 4 & $14 \%$ \\
CNC & 5 & $17 \%$ \\
Both & 15 & $52 \%$ \\
& Unkown & 4 & $14 \%$ \\
Other & 1 & $3 \%$ \\
\hline
\end{tabular}

\subsection{Knowledge and Description of Health Effects}

Differences were found between the experts' and workers' descriptions of the health effects that can be caused by MWF exposure in the workplace (see Table 2). In particular, only $28 \%$ of the workers were able to describe symptoms that could occur in the lungs as a result of MWF exposure (such as cough, asthma, bronchitis, difficulty breathing). The majority of the experts described respiratory issues in detail, providing a description of symptoms and specific medical terminology of diseases associated with MWF exposure such as such as hypersensitivy pneumonitis (HP), occupational asthma and decreased lung function. Only two of the workers were able to describe asthma as a potential condition from MWF exposure, one mentioned decreased lung function, and none mentioned HP.

While unable to provide any specific terms or symptoms, a further $45 \%$ percent of workers were able to identify "the lungs" as potential site of health problems. Of note, nine of the workers (31\%) described having personal experience with either a lung effect from MWF exposure or "feeling" MWF mists in their lungs.

There was greater concurrence between experts' and workers' awareness of specific dermal conditions that can occur as a result of MWF exposure, including rash, dry hands, itchy hands, dermatitis and eczema. Sixty-two percent of workers could identify a specific dermal health effect such as eczema, although a further $31 \%$ were only able to identify "the skin" in general as a potential site for health effects. Forty percent of the workers said that they had experienced adverse effects on their hands from MWF exposure.

Four of the experts (44\%) discussed the association between cancer and MWF exposure, although proportionally fewer (17\%) of the workers described MWFs as cancer-causing agents. Of the workers who described cancer, there was a general tendency to mention smoking and its carcinogenic potential in the same discussion.

There were health effects that workers described that experts did not, particularly irritation that could occur in eyes. Two workers also suggested that MWF could affect blood.

Within the cohort of workers, $21 \%$ stated that MWFs were not harmful to health, even though in some cases these workers did note that MWF exposure could cause skin problems. Finally, there were two people in the worker group who stated that they were unaware of any potential health effects of MWF exposure. 
Table 2. Description of Health Effects, Experts and Workers

\begin{tabular}{|c|c|c|}
\hline Health Effects & $\begin{array}{l}\text { Workers } \\
(\mathrm{n}=29) \%\end{array}$ & $\begin{array}{l}\text { Experts } \\
(n=10) \%\end{array}$ \\
\hline $\begin{array}{l}\text { Described specific health effects } \\
\text { that can occur in the lungs }\end{array}$ & $28 \%$ & $70 \%$ \\
\hline $\begin{array}{l}\text { Described specific health effects } \\
\text { that can occur on the skin }\end{array}$ & $62 \%$ & $70 \%$ \\
\hline $\begin{array}{l}\text { Described a relationship between } \\
\text { MWF exposure and cancer }\end{array}$ & $17 \%$ & $40 \%$ \\
\hline Central Nervous system Depression & $3 \%$ & $10 \%$ \\
\hline Eye Irritation & $17 \%$ & $0 \%$ \\
\hline Problems with blood & $7 \%$ & $0 \%$ \\
\hline Poisonous & $3 \%$ & $0 \%$ \\
\hline $\begin{array}{l}\text { Stated that MWFs do NOT cause } \\
\text { health effects }\end{array}$ & $21 \%$ & $0 \%$ \\
\hline
\end{tabular}

\subsection{Sources of Information}

Experts and workers were asked slightly different questions regarding sources of health and safety information in the workplace. Table 3 presents responses to the open ended questions "How do you think that workers learn about new scientific advances in MWFs? and "How about safety issues around MWFs?”. While $40 \%$ of workers noted that occupational health and safety training was a source of information, the same number of experts did not think that workers received such information at all. Material Safety Data Sheets (MSDS) were ranked fairly low as information sources for workers amongst the scientific experts.

Table 3. Expert answers to: How do workers learn about new health and safety issues and advances? $(n=10)$

\begin{tabular}{ll}
\hline Expert Answer & $\%$ \\
\hline “They don't” & 40 \\
Occupational health and safety training & 40 \\
Trade media (magazines, pamphlets) & 30 \\
Union & 30 \\
General news media & 10 \\
MSDS & 10 \\
Gov't agencies & 10 \\
\hline
\end{tabular}

Table 4 shows the responses to the following open ended question that was posed to workers: "If you were going to learn about the health effects of metal working fluid exposure, or maybe some of the hazards that you are exposed to in your shop, where would you go for this sort of information?" Suppliers and manufacturers were the most referred to sources, followed by MSDSs, which is in sharp contrast to the responses of the experts. Other workers and the internet were also major sources for workers not described by the experts.
Table 4. Worker answers to question regarding main sources of information used

\begin{tabular}{ll}
\hline Worker Answer $(\mathrm{n}=29)$ & $\%$ \\
\hline Suppliers and manufacturers & 86 \\
MSDSs & 69 \\
Managers or other workers & 66 \\
The internet & 48 \\
Health and safety committee & 41 \\
Government organizations & 34 \\
Container labels & 28 \\
\hline
\end{tabular}

Workers were also asked "what person, agency or group would you trust the most for information on MWFs, either about the product or possible associated health effects?" The responses to this question, shown in Table 5, indicate that most workers trust WorkSafeBC, British Columbia's workers compensation board. Various levels and departments within government were the next most trusted, followed by MSDSs and manufacturers/suppliers.

Table 5 Workers' Trusted Sources

\begin{tabular}{ll}
\hline Worker Answer $(\mathrm{n}=29)$ & $\%$ \\
\hline WorkSafeBC & 31 \\
Government & 17 \\
MSDS & 14 \\
Manufacturer/supplier & 14 \\
Other workers & 3 \\
Union & 3 \\
Researchers & 3 \\
Don't know & 3 \\
\hline
\end{tabular}

Table 6 presents results of the questions asked to experts on how they had attempted to communicate the results of their MWF research. Most had provided information to either workplace management or to a government health and safety agency. Half reported that they had talked to workers directly about MWF health effects and only one reported talking to physicians.

Table 6 Expert Communication Pathways

\begin{tabular}{ll}
\hline Expert Answer $(\mathrm{n}=10)$ & $\%$ \\
\hline Workplace management & 70 \\
Government health and safety agencies & 60 \\
Workers & 50 \\
Industry/Suppliers & 40 \\
Unions & 40 \\
Government (other than safety agency) & 10 \\
Physician & 10 \\
\hline
\end{tabular}




\section{DISCUSSION}

\subsection{Health Effects}

Good workplace risk communication requires that workers receive information about the chemicals that they use and that workers understand the potential health effects that these chemicals can cause. As Schulte et al. (Schulte et al., 2003) states "effective transfer, receipt and utilization of occupational health and safety information will only be realized to the extent to which recipients actually can understand the information transmitted" (p.522). The results of this research suggest that while workers are aware that they are being exposed to MWFs during the course of their jobs, most have only a generalized understanding of how these compounds may affect the body. Such results are not unique to this research and have been found in other occupational health research such as that conducted by Sadhra (Sadhra, Petts, McAlpine, Pattison, \& MacRae, 2002).

Of concern were the findings that three quarters of the workers queried were unable to provide any detail about the effects that MWF might have on their respiratory tract. In addition, they did not link symptoms such as cough, difficulties breathing, phlegm, asthma, and bronchitis to MWF exposure. Researchers such as Nowak et al (Nowak \& Angerer, 2007) indicate that one of the problems of identifying occupational disease is that fact that the symptoms aren't necessarily correlated directly in time with an exposure and as such, may happen after a worker has left the workplace. This mechanism, coupled with a lack of awareness on the part of the workers about the types of symptoms that MWFs can cause, makes the correct diagnosis of occupational respiratory disease very challenging. Gupta et al (Gupta \& Rosenman, 2006) has suggested that hypersensitivity pneumonitis (HP) rates in the US are most likely under-reported due to factors such as inadequate disease recognition. Without information about workers' occupational and environmental exposures, doctors may misdiagnose conditions like HP as atypical pneumonia. The review by Santos et al (Santos et al., 2007) of diagnostic factors for occupational asthma found that lack of awareness of the association between symptoms and workplace exposures was one of the most significant factors contributing to diagnostic delays.

The workers' descriptions of dermal effects were markedly different from those of respiratory problems, with a majority of workers being able to describe distinct symptoms of MWF exposure such as rash, itchiness and dry hands. These results may be due to the fact that many of the workers had actually experienced these problems personally, or had known others who had these types of skin problems. Indeed, occupational skin diseases are the most commonly reported work-place related conditions (Lushniak, 2003). Research by Sadhra et al (Sadhra et al., 2002) found that workers tended to talk more easily and automatically about more common health problems rather than those that were considered more serious. Indeed, many workers in this study noted that they had skin effects, yet these weren't necessarily considered serious, or even real "health" effects, even though they were eligible for compensation. For example, when asked about the effects of short-term exposure, one worker replied:

\footnotetext{
“As far as sick...I wouldn't call what I had being sick. It's just, you know, you have a rash on your hand and I did have time off because of that."
}

There were relatively few workers who described health effects that were erroneous, indicating that most were at least aware of the correct areas of the body that MWFs could affect. Of particular interest from the worker data was the issue of eye irritation. This effect was not noted by any of the experts, even though MSDSs for MWF list eye irritation as a potential health effect. In fact, a review of MSDS for metal working fluids found that there was more information about eye irritation on some sheets than potential respiratory effects. A review of the published literature revealed no research focused specifically on eye irritation and MWF exposure.

\subsection{Information Sources}

The flow or transfer of information between the "expert" realm and the "workplace" realm appeared to be hampered by a number of barriers in this study. In particular, the responses from experts and workers on the topic of where to find information on MWFs showed a significant disconnect between the groups. None of the workers were ignorant of potential sources of information on the health effects of MWFs, although $40 \%$ of experts believed that workers did not learn about health and safety information. Workers also identified MSDSs as important information sources, while only $10 \%$ of experts believed that workers learned from MSDSs (this finding is in keeping with the earlier discussion of effects of MWF on eyes). Suppliers and manufacturers were the most commonly mentioned information source by workers, with $86 \%$ of workers stating that they would go to suppliers and manufacturers for information. In contrast, none of the experts mentioned suppliers and manufacturers. These results are consistent with a study by Sadhra et al (2002), which found considerable differences 
between the information sources mentioned by experts and by workers in the electroplating industry.

These results suggest that many MWF experts perceive knowledge translation processes as "broken" or non-existent, even though experts did report efforts to communicate their research results to audiences beyond the academic/scientific community. The majority of experts reported that they communicated research results to workplace management; however, most experts were disillusioned about their communication efforts and the potential of these processes to be translated to those at risk. Experts expressed a variety of opinions as to why they felt that their efforts to send risk messages to workers were ineffective. A number of experts directed frustration at workplace managers and regulatory bodies for seemingly not heeding scientific advice:

“...the communication [with workplace management] was unsuccessful in that I didn't get any feedback [ ...] on what happened next."

"I think we presented [the regulatory body] with what we thought were positive findings but, I think, since then we've been a little disappointed that they haven't really capitalized on the research as much as they might have done."

"I have to say that we have been very disappointed with the way that the [regulatory agency] have failed to publish the reports that we did in a lot of this work."

This perceived lack of responsiveness from decision-makers who are actually in a position to effect changes in the workplace was problematic for experts. This frustrating situation may cause them to abandon their efforts to communicate with decisionmakers. There is evidence that research dissemination and uptake is hampered both by researchers' imperfect understanding of decisionmaking contexts, as well as by the organizational and/or political pressures facing decision-makers such as regulatory bodies. Lomas (Lomas, 1996) suggests that structures to support and improve ongoing knowledge translation and exchange between researchers and decision-makers are needed to speed the process of research dissemination and uptake. He suggests a cultural shift involving new organizational models for both decision-makers and researchers, as well as enhanced funding to support ongoing knowledge translation between both groups.

Other experts, when discussing their communication activities, expressed a level of discomfort with, or lack of knowledge of, appropriate lay communication techniques.
"I think [communication to workers] is something that scientists overall have to do a lot more of. They have to interest a lay audience in what they do, and it's an area, I think, we all need to do a lot more in."

"I'd like to know a way of getting [health and safety] information over to people so they actually took heed of advice before they actually got problems."

"Expert: I figure the way that I am doing it, I would admit, is not the best. I think a program to directly give your results to the labourers would be an ideal pathway to go. It is not something that our department routinely does - if ever - except for communities. Talking to the workers - that's not something I have ever done and I'm not familiar with that many people who have.

Interviewer: I see. Do you have an idea of how you would go about developing such a program?

Expert: No. Being an academic, unless there was funding, I wouldn't know."

These comments demonstrate experts' recognition of their own role in the risk communication process and their awareness that different communication techniques are necessary to reach worker audiences. This suggests a need for appropriate training, resources, and incentives to participate in non-traditional knowledge translation efforts. Some funding agencies, such as Canada's Canadian Institutes for Health Research, are now actively promoting such efforts by requiring academic proposals to have knowledge translation plans, and by providing funding for research into effective knowledge translation practices (Canadian Institutes of Health Research, 2003).

\subsubsection{Trust in Information Sources}

The role of trust in mediating how risk messages are perceived, attended to, and acted upon has been widely acknowledged in risk perception and communication research. Studies have found that distrust heightens lay concerns and responses to risk messages, and leads to questioning of the actions of risk regulators and authorities (Cvetkovich \& Löfstedt, 1999). Lay perceptions of trust and credibility in risk messengers are dependent on three factors: perceptions of knowledge and expertise; perceptions of openness and honesty; and perceptions of concern and care (Kasperson, Golding, \& Tuler, 1992). These factors were evident in workers' discussion of trusted information sources.

Worker responses to the question about what person, agency or group they would trust the most for information on MWF reveal a further disconnect between the most used sources of information and the most trusted sources of information. Manufacturers and suppliers were mentioned most 
often as a source of information, yet the provincial workers' compensation board was reported to be the most trusted source. Indeed, many workers specifically noted that they did not trust manufacturers and suppliers information source even though they used it. The reason for this distrust is apparent in the comment of one worker that "they're just trying to sell you something." Since trust is seen as a prerequisite to effective risk communication (Kasperson et al., 1992), this demonstration of distrust in manufacturers is problematic. Although workers may receive information on MWFs and their potential impacts on health from these sources, they may disregard recommendations or ignore precautionary steps due to a perception of dishonesty in the risk messengers.

Workers identified the provincial workers compensation board as their most trusted source of information. Workers described the board as "unbiased," "independent," and "non-profit." Many workers pointed out that it was in the board's best (financial) interest to prevent workers from becoming sick, and thus it was also in their best interest to provide accurate and balanced information. A number of workers also mentioned that the board had resources to conduct research and to make evidence-informed decisions. Thus, the board fits the factors of expertise, honesty, and concern put forward by Peters et al (Peters, Covello, \& McCallum, 1997). These results suggest that risk messages delivered by the workers compensation board may be more likely to be trusted, and thus acted upon. However, not one worker mentioned the Board as a source of information that they would use to learn about hazards associated with MWF. Thus, efforts would need to be made in order to actively disseminate information from this source to workers.

\section{STRENGTHS AND LIMITATIONS}

A strength of this mental models approach rests on the ability to develop a detailed representations of occupational hazards from different perspectives. However, these representations rest on interview data that cannot be assumed to be a direct reflection of participants' conceptual understandings. Participants may not mention implicit knowledge of hazards or workplace behaviour, or may edit their comments based on what they consider appropriate for a conversation with a researcher.

This study benefited from interviews with a comprehensive range of experts who have studied MWFs from various disciplinary angles, including occupational hygiene, respiratory medicine, environmental toxicology, etc. The research community in this area is small, resulting in a small sample size drawn from around the world.

In contrast, the sample of workers was relatively large, but was drawn only from the province of British Columbia, Canada. Thus, the workers' conceptual representations of MWF regulation and use may differ from experts' due to geographic specificities in regulation, economics, and use. In addition, some of the workers were also participants in an ongoing study of respiratory health of tradespeople. Thus, these respondents might have been more aware of the respiratory health effects of MWF (although this hypothesis is not supported by the results of this study).

\section{CONCLUSION}

The results of this research have implications not only for workers but also for the broader fields of occupational health and safety, occupational medicine and disease surveillance, and occupational knowledge translation. Through this Mental Models process we have determined that there is some overlap between how workers and experts understand the effects of MWFs, particularly in the area of dermal exposure, but that much more attention needs to be paid to providing workers with a more comprehensive understanding of the effects of MWF on the respiratory tract.

This study has also illuminated a number of important disconnects between how workers do receive information as opposed to how they would like to receive information, an important distinction that may be impeding the awareness and management of workplace risks. Additionally, this study uncovered a degree of frustration on the part of experts in their attempts to communicate their findings and a relatively bleak view of the current workplace communication milieu for the worker. Neither of these conditions, as they stand, will enhance the communication and exchange of MWF exposure data in the occupational context.

At the outset of this study, manufacturers and suppliers were not expected to play such a key role in the dissemination of health and safety information on MWFs. These unexpected findings have led to a third phase of interviews with a selection of manufacturers and suppliers. The results of these interviews are expected to shed additional light onto the role that this group plays in the communication of health and safety issues relating to MWF.

Acknowledgements: The authors would like to thank Dr. Susan Kennedy, Emily Carpenter, Reid Chambers and Natasha McCartney for their 
assistance with this paper. This project was funded in part by the Canadian Institute for Health Research. 


\section{REFERENCES}

Canadian Institutes of Health Research,. (2003). Knowledge translation overview. Retrieved June 29, 2006, from http://www.cihr-irsc.gc.ca/e/7518.html

Cox, P., Niewohmer, J., Pidgeon, N., Gerrard, S., Fischhoff, B., \& Riley, D. (2003). The use of mental models in chemical risk protection: Developing a generic workplace methodology. Risk Analysis : An Official Publication of the Society for Risk Analysis, 23(2), 311-324.

Cvetkovich, G. T., \& Löfstedt, R. (1999). In Cvetkovich G. T., Löfstedt R. (Eds.), Social trust and the management of risk. London: Earthscan.

Gupta, A., \& Rosenman, K. D. (2006). Hypersensitivity pneumonitis due to metal working fluids: Sporadic or under reported? American Journal of Industrial Medicine, 49(6), 423-433.

Kasperson, R. E., Golding, D., \& Tuler, S. (1992). Social distrust as a factor in siting hazardous facilities and communicating risk. Journal of Social Issues, 48(4), 161187.

Kennedy, S. M., Chan-Yeung, M., Teschke, K., \& Karlen, B. (1999). Change in airway responsiveness among apprentices exposed to metalworking fluids. American Journal of Respiratory and Critical Care Medicine, 159(1), 87-93.

Lomas, J. (1996). Improving research dissemination and uptake in the health sector: Beyond the sound of one hand clappingCentre for Health Economics and Policy Analisys. Department of Clinical Epidemiology and Biostatics. McMaster University.

Lushniak, B. D. (2003). The importance of occupational skin diseases in the united states. International Archives of Occupational and Environmental Health, 76(5), 325-330.

Morgan, M. G. (2002). Risk communication: A mental models approachCambridge University Press.

Niewohner, J., Cox, P., Gerrard, S., \& Pidgeon, N. (2004a). Evaluating the efficacy of a mental models approach for improving occupational chemical risk protection. Risk Analysis : An Official Publication of the Society for Risk Analysis, 24(2), 349-361.

Niewohner, J., Cox, P., Gerrard, S., \& Pidgeon, N. (2004b). Evaluating the efficacy of a mental models approach for improving occupational chemical risk protection. Risk Analysis : An Official Publication of the Society for Risk Analysis, 24(2), 349-361.

Nowak, D., \& Angerer, P. (2007). Work-related chronic respiratory diseases--current diagnosis. [Arbeitsbedingte chronische Atemwegserkrankungen. "Bekommen Sie am Wochenende besser Luft"?] MMW Fortschritte Der Medizin, 149(49-50), 37-40.

Peters, R. G., Covello, V. T., \& McCallum, D. B. (1997). The determinants of trust and credibility in environmental risk communication: An empirical study. Risk Analysis, 17(1), 43-54.

Sadhra, S., Petts, J., McAlpine, S., Pattison, H., \& MacRae, S. (2002). Workers' understanding of chemical risks: Electroplating case study. Occupational and Environmental Medicine, 59(10), 689-695.

Santos, M. S., Jung, H., Peyrovi, J., Lou, W., Liss, G. M., \& Tarlo, S. M. (2007). Occupational asthma and workexacerbated asthma: Factors associated with time to diagnostic steps. Chest, 131(6), 1768-1775.

Schulte, P. A., Okun, A., Stephenson, C. M., Colligan, M., Ahlers, H., Gjessing, C., et al. (2003). Information dissemination and use: Critical components in occupational safety and health. American Journal of Industrial Medicine, 44(5), 515-531.

Strauss, A. L., \& Corbin, J. M. (1998). Basics of qualitative research: Techniques and procedures for developing grounded theorySage Publications. 